\title{
CITIZENS PARTICIPATION IN ADDRESSING LOCAL PROBLEMS: A CASE STUDY OF REPUBLIC OF MACEDONIA
}

Jorde JAKIMOVSKI, Institute of Sociological, Political and Juridical Research, University Ss Cyril and Methodius, Macedonia, Bul. "Partizanski odredi” bb 1000 Skopje, Republic of Macedonia, e-mail: jakjor@isppi.ukim.edu.mk

\begin{abstract}
The paper discusses the level of satisfaction of the local government performance and certain forms of citizen's participation in the improvement of the quality of life in the rural communities, such as creating new job positions, improvement of the infrastructure, creating better opportunities for the children, and decreasing of the poverty. Politicians often make big promises before elections while talking about democracy, rule of law and citizens well-being. After their election, however, they forget about the problems of their fellow citizens. Citizens then feel helpless, fall in apathy and hopelessness, and take a distance from politics and the vital questions for their rural community. The paper will show some data related to these issues gathered from a research conducted by the author in 2016 on a representative sample of 640 respondents on the territory of Republic of Macedonia. The research results show the current situation of the citizen's satisfaction from the local government with respect to the solutions of water supply and sewerage, transport of citizens, opening of new jobs, building of social services facilities, opportunities for culture and recreational activities, and they ways in which the citizens influenced the local government. The results mostly reflect dissatisfaction with the work of the local government in addressing local problems, the underdeveloped mechanism of public participation, low level of human capital in rural local governments and other problems.
\end{abstract}

Keywords: forms of participation, satisfaction, local government, rural development, Republic of Macedonia

\section{INTRODUCTION}

"The rural community is considered agricultural and the urban community is considered a professional and production area of the secondary and tertiary sector. Other rural-urban differences arise from these basic variables, for example: community size, population density, heterogeneity, socio-psychological homogeneity, social differentiation and stratification, mobility, environment and interaction systems (Jakimovski, 2006: 11). Industrialization in the Republic of Macedonia had a major impact on the village-city migration and left negative consequences on the rural communities. Particularly affected were the more remote hilly and mountainous rural communities. Unemployment forced people from these settlements to migrate permanently to the nearest urban and suburban areas where they received employment. Additional cause for the permanent migration was the poor infrastructure (unasphalted roads, irregular transport, walking for several hours to the first bus stop and the like) preventing daily travel to the workplace.

\section{REGIONAL POLICY}

The territory of the Republic of Macedonia is divided into 8 regions (Vardar, Eastern, South-Western, SouthEastern, Pelagonia, Polog, North-Eastern and Skopje Region).

The territory of the Republic of Macedonia covers an area of $25713 \mathrm{~km}^{2}$, and based on the population estimates from the State Statistical Office in 2016 (status of 30 June 2016) the population included 2072490 inhabitants, or 80.6 inhabitants per $\mathrm{km}^{2}$.

The Assembly of the Republic of Macedonia in 2007 adopted the Law on Balanced Regional Development which defines the key policy objectives to encourage balanced regional development including: balanced and sustainable development on the whole territory of the Republic of Macedonia, reduction of disparities between and within the planning regions, increasing the competitiveness of the regions, the preservation and development of special identity of the planning regions and support to the inter-municipal and cross-border cooperation of the local self-government (Article 3 of the Law). However, in the Republic of Macedonia, considerably more attention is dedicated to structural problems than to the regional development although regional development is a structural problem in the full meaning of the word. The effects of privatization are far lower in underdeveloped regions, due to underdeveloped infrastructure, low level of human capital and low level of development of society activities.

Copyright (C) 2017 The Authors. Published by Aleksandras Stulginskis University. This is an open-access article distributed under the terms of the Creative Commons Attribution License (CC-BY 4.0), which permits unrestricted use, distribution, and reproduction in any medium, provided the original author and source are credited. 
Table 1: Same basic indicators (Republic of Macedonia $=100.00)$

\begin{tabular}{|c|c|c|c|c|c|}
\hline \multirow{2}{*}{ Republic of Macedonia } & \multirow{2}{*}{$\begin{array}{l}\text { Gross value added, } \\
2014 \\
100.00\end{array}$} & \multirow{2}{*}{$\begin{array}{l}\text { Gross fixed capital } \\
\text { formation, } \\
2014 \\
100.00\end{array}$} & \multirow{2}{*}{$\begin{array}{l}\text { Average net paid per } \\
\text { employee, } 2016 \\
100.00\end{array}$} & \multicolumn{2}{|c|}{ Number of villages } \\
\hline & & & & 1715 & 100.00 \\
\hline Vardar region & 7.97 & 5.95 & 79.22 & 167 & 9.74 \\
\hline East region & 8.24 & 8.23 & 74.75 & 253 & 14.75 \\
\hline Southwest region & 7.89 & 7.67 & 89.71 & 278 & 16.21 \\
\hline Southeast region & 10.00 & 5.62 & 78.35 & 184 & 10.73 \\
\hline Pelagonia region & 11.07 & 6.74 & 92.20 & 339 & 19.77 \\
\hline Polog region & 7.09 & 5.71 & 96.16 & 181 & 10.55 \\
\hline Northeast region & 4.96 & 2.06 & 75.87 & 188 & 10.96 \\
\hline Skopje region & 42.78 & 58.02 & 117.46 & 125 & 7.29 \\
\hline
\end{tabular}

Source: My calculations \& State Statistical Office ,Regions of the Republic of Macedonia, 2017 and Book 1, Total population number oer sex and age- final data per populated places, Statistics Bureau of the Republic of Macedonia, Skopje, 2004.

The complete area of the North-East region creates approximately $5 \%$ of the newly created value in the Republic of Macedonia, while the Skopje region $43 \%$.

Defeating is also the structure of investments in fixed assets, which are not only not in accordance with the proclaimed goals of the strategy, but increasingly contribute to the distancing from them. Approximately 58\% of the total investments in fixed assets in the Republic of Macedonia, have been allocated to the Skopje region, whereas the Northeast region participates with only $2 \%$ of the total investments.

Namely, the Eastern region has an average net salary per employee at $74 \%$ of the national average and Northeast region $76 \%$.

The Regional Development Strategy of the Republic of Macedonia 2009-2019 adopted in 2009 (Official Gazette of the Republic of Macedonia No. 119/2009) highlights two main strategic goals, as follows:

- Competitive planning regions which are characterized by dynamic and sustainable development and

- Greater demographic, economic, social and spatial cohesion among and within the planning regions in the Republic of Macedonia.

The overview that follows clearly illustrates the fact that the most important goals in the Regional Development Strategy of the Republic of Macedonia, include the stimulation of economic growth, development of contemporary and modern infrastructure, raising the level of human capital, creating competitive advantages, environmental protection, demographic revitalization and balanced distribution of the population, building of functional spatial structures, increased and more balanced distribution of investment and employment, raising the level of social development, support for areas with specific development needs, developing of cross-border and mutual cooperation and capacity building for planning and implementation of the development of planning regions, which have not been achieved. Not only is the situation deteriorating, but negative economic and demographic trends are even intensified.

The biggest and most serious cause for clearing of certain regional units are probably low living standards and the uncertain existence of the people who live in those regions.

\section{Rural processes (migration, de-agrarization)}

In the Republic of Macedonia about $86 \%$ of the territory is rural and more than $40 \%$ of the population lives there (Jakimovski, 2006).

Table 2: Size of villages

\begin{tabular}{|l|l|l|l|l|}
\hline \multirow{2}{*}{ Number of population } & 1994 & $\%$ & 2002 & Number \\
\cline { 2 - 5 } & Number & 7.1 & 145 & 8.5 \\
\hline Completely moved out & 121 & 33.5 & 630 & 36.7 \\
\hline Up to 100 inhabitans & 573 & 22.6 & 323 & 18.8 \\
\hline $1001-300$ " & 387 & 19.3 & 318 & 18.6 \\
\hline $301-800$ & 17.5 & 299 & 174 \\
\hline$>801$ & 332 & 100.0 & 1715 & 100.0 \\
\hline Total & 1715 & &
\end{tabular}

Source: My calculations \& State Statistical Office, Total number of population, households, flats and farming economies per municipalities and inhabited places according to administrative and territorial division from 1996, Book V, Skopje, 1997, pp. 13-45, and Book 1, Total population number oer sex and age- final data per populated places, Statistics Bureau of the Republic of Macedonia, Skopje, 2004.

In the structure of rural communities with a population of up to 100 inhabitants an increase of $33.5 \%$ to $36.7 \%$ has been recorded, while in the villages of 101-300 inhabitants and 301-800 inhabitants the number of villages is decreasing.

Migration, and especially the permanent migration that occurs most often due to the lack of financial resources, the unfavourable living conditions in the villages, unemployment consequently leads to the abandonment of agriculture as an activity. Cities that become industrial centres are more appealing centres for greater opportunities and better living conditions. Thus, a large segment of the arable land and cattle remain abandoned and uncultivated, and people start to settle in the cities and in the unurbanized settlements where there are no conditions for cattle breeding. This situation that arises as a result of urbanization, accelerated economic, cultural development and industrialization, on the one hand leaves the migration village-city as a consequence, but on the other hand it leads to the creation of several un-urbanized "wild" 
settlements. "Due to migration in many settlements, the number of population has decreased, so the number of settlements up to 99 inhabitants compared to 1948 increased by 5.5 times in 2002" (Jakimovski, 2006). Rural communities of up to 300 inhabitants and migrated villages are 1034 or $64 \%$ of the total number of villages (2002). These villages are the most numerous and only 126246 inhabitants live there. Large rural communities over 800 inhabitants are 242 (15\%), and they account for $58 \%$ of the total rural population "(Zikov, 2006: 5).

The migration from rural communities to urban areas is the most significant in the period from 1961 to 1971 . "The mechanical influx in the cities was a particularly important source for the increase in the urban population until 1971 (Uzunov, Georgiev, Nestorovski, 1988: 137). In this period, the villages were massively abandoned, which contributed to increasing the differences in the age, educational structure and reduction of the population density of the village population. As a result of these changes there are significant differences between rural and urban areas, i.e. between the village and the city. The establishment of factories and the creation of a working class has contributed, on the one hand, to the reduction of the rural population, and on the other hand, as a result, there is a decrease in the number of people who are engaged in agriculture. The non-synchronization of urbanization and industrialization in the period 1971-1981 led to the outflow of the population from agriculture and the village more than it was required by the industry and the cities. These processes have led to massive abandonment of villages and agriculture as an activity. The abandonment of villages, the large number of migrations, permanent or on a daily basis and the unfavourable infrastructure affected the neglecting of agriculture. This can also be seen from the statistical data that indicated a decrease in the rural and agricultural population. In 1948, the percentage of the rural population was $72.4 \%$, and of the agricultural population, $71.52 \%$, in 1961 the percentage of the rural population decreased to $61.4 \%$ and of the agricultural population to $51.52 \%$, in 1971 the rural population additionally decreases to $48.8 \%$ and the agricultural population is reduced to $39.89 \%$. This trend of decreasing the rural and agricultural population continued in 1981 when the rural population accounted for $46.1 \%$ and the agricultural population for $21.69 \%$ and in 1994 when the rural population accounted for $40.2 \%$ and the agricultural population for $11.79 \%$. In 2002 , when the last census was conducted, the percentage of the rural population was 40.6\% (Jakimovski, 2004).

The unfavourable qualitative features of urbanization were especially visible in the period after 1991, when, in conditions of transition, the economy declined or stagnated.

In the new social and political conditions created by the transitional changes, in the rural areas there is a slow and non-synchronized economic and social development. In some rural communities, urbanization is accelerated, in others it is slower, and in third, there is no minimum communal infrastructure. The analyses show that the built infrastructure is not enough in its scope and quality and significantly lags behind the communal equipment of the urban areas. More rural communities are still not covered by water supply, or there are no roads built there, no sewage network and the like.

There is no traditional link between the low social standard and the settlement. There is a connection between the environment (place of residence) and the social group. In other words, between the physical characteristics of the place of residence and the characteristics of the population, there are no special connections, but there is an emergence that some social categories of the population due to some reasons concentrate (are segregated) in some areas - and thus determine the typology of occurrence in the place in which they live. That means that the poor are not poor because they live in some environments, but because they have low incomes, lack of goods and services, and their social power is low.

Unlike the cities, the rural communities have lower per capita income, people living in rural areas have fewer skills and abilities, the services are less developed, and the care for the environment is usually an expense. (Marius Lazdinis, The EC's approach to rural development, with an emphasis on pre-accession period).

In general, it can be said that a greater percentage of the old and less educated workforce lives in the village, that population is more exposed to the consequences of transition, it has a smaller opportunity to change its own material position and social status.

"Household members who work on individual farms mostly consists of people without education, peple with incomplete primary education and people with completed primary education (47.2\%)" ( Jakimovski, 2017:5934).

A large segment of the population with low social status is concentrated in rural areas, and if the elementary living conditions are not improved, their number may increase, as people in rural areas make little use of the benefits of the common social standard.

This is especially typical of the remote areas of the city which have no asphalted roads, no public transport, they cannot use services in education, health, etc. They are forced to invest more funds for the use of communal and social infrastructure services. Also, for people living in these environments, there is a limitation of opportunities to participate in the economic life. They earn $89 \%$ of the income generated by those who live and work in cities (Statistical review: Incames, expenditures and prices, 2015), have a harder access to financial institutions, they find it more difficult to use the services of the state administration in establishing a bu siness and the like.

\section{Citizens' positions of sasatisfaction with the work of the local government}

On the question of satisfaction with the work of the local government for finding solutions for opening new jobs, in water supply and sewage, for transport/carriage, construction and maintenance of roads, accessibility of social services (schools, kindergartens, hospitals) and shops and for opportunities in cultural and sporting activities, the majority of the respondents think that they are "satisfied" with the work of the local government in finding solutions in the water supply and sewage system $(51.20 \%)$.

The determination of the same option "satisfied" in other activities is as follows: solutions for the availability of social services (schools, kindergartens, hospitals) and shops $(49.50 \%)$, solutions for transport and maintenance of roads (47.00\%), solutions for opportunities in culture and sports activities (36.50\%) and solutions in finding new jobs (36.00\%). 
Table 3: Satisfaction with the work of the local government

\begin{tabular}{|l|c|c|c|c|}
\hline & Satisfied & Dissatisfied & Unknown & Total \\
\hline Finding solutions for opening new jobs & 36.00 & 52.40 & 11.60 & 100.00 \\
\hline $\begin{array}{l}\text { Finding solutions in the water supply and } \\
\text { sewage system }\end{array}$ & 51.20 & 37.80 & 10.90 & 100.00 \\
\hline $\begin{array}{l}\text { Finding solutions for transport/carriage, } \\
\text { construction and maintenance of roads }\end{array}$ & 47.00 & 43.30 & 9.70 & 100.00 \\
\hline $\begin{array}{l}\text { Solution for the availability of social services } \\
\text { schools, kindergartens, hospitals) and shops }\end{array}$ & 49.50 & 40.50 & 10.00 & 100.00 \\
\hline $\begin{array}{l}\text { Solution for Opportunities in cultural and } \\
\text { sporting activities }\end{array}$ & 36.50 & 51.20 & 12.30 & 100.00 \\
\hline
\end{tabular}

Table 4: Satisfaction with the work of the local government according region

\begin{tabular}{|c|c|c|c|c|}
\hline \multirow{2}{*}{ Regions } & Satisfied & Dissatisfied & Unknown & Total \\
\hline & \multicolumn{4}{|c|}{$\begin{array}{l}\text { Satisfaction with the work of the local government for finding solutions for opening new jobs } \\
\mathbf{X}^{2}=203476\end{array}$} \\
\hline Vardar region & 56.20 & 28.80 & 15.00 & 100.00 \\
\hline East region & 56.20 & 28.80 & 15.00 & 100.00 \\
\hline Southwest region & 45.10 & 43.60 & 11.30 & 100.00 \\
\hline Southeast region & 41.10 & 35.10 & 23.80 & 100.00 \\
\hline Pelagonia region & 46.20 & 53.80 & 0.00 & 100.00 \\
\hline Polog region & 20.00 & 77.50 & 2.50 & 100.00 \\
\hline Northeast region & 8.80 & 82.40 & 8.80 & 100.00 \\
\hline Skopje region & 15.00 & 66.70 & 17.30 & 100.00 \\
\hline \multicolumn{5}{|c|}{$\begin{array}{l}\text { Satisfaction with the work of the local government for finding solutions in the water supply and sewage system } \\
\mathbf{X}^{\mathbf{2}=192650}\end{array}$} \\
\hline Vardar region & 65.10 & 13.70 & 21.20 & 100.00 \\
\hline East region & 70.00 & 20.00 & 10.00 & 100.00 \\
\hline Southwest region & 70.10 & 26.10 & 3.80 & 100.00 \\
\hline Southeast region & 55.00 & 25.00 & 20.00 & 100.00 \\
\hline Pelagonia region & 51.30 & 47.60 & 1.10 & 100.00 \\
\hline Polog region & 38.80 & 45.00 & 16.20 & 100.00 \\
\hline Northeast region & 22.50 & 72.50 & 5.00 & 100.00 \\
\hline Skopje region & 37.50 & 52.50 & 10.00 & 100.00 \\
\hline
\end{tabular}

Satisfaction with the work of the local government for finding solutions for transport/carriage, construction and maintenance of roads $\quad \mathbf{X}^{2}=238022$

\begin{tabular}{|l|c|c|c|c|}
\hline Vardar region & 61.20 & 25.00 & 13.80 & 100.00 \\
\hline East region & 53.80 & 35.00 & 11.20 & 100.00 \\
\hline Southwest region & 80.00 & 16.20 & 3.80 & 100.00 \\
\hline Southeast region & 47.40 & 28.80 & 23.80 & 100.00 \\
\hline Pelagonia region & 47.60 & 52.40 & 0.00 & 100.00 \\
\hline Polog region & 33.80 & 56.20 & 10.00 & 100.00 \\
\hline Northeast region & 22.50 & 72.50 & 5.00 & 100.00 \\
\hline Skopje region & 30.00 & 60.00 & 10.00 & 100.00 \\
\hline
\end{tabular}

Satisfaction with the work of the local government for finding solutions for the availability of social services (schools, kindergartens,

\begin{tabular}{|l|c|c|c|c|} 
hospitals) and shops & $\mathbf{X}^{\mathbf{2}=262} 323$ & 25.00 & 11.20 & 100.00 \\
\hline Vardar region & 63.80 & 20.00 & 13.70 & 100.00 \\
\hline East region & 66.30 & 18.70 & 5.00 & 100.00 \\
\hline Southwest region & 76.30 & 35.00 & 21.30 & 100.00 \\
\hline Southeast region & 43.70 & 56.20 & 0.00 & 100.00 \\
\hline Pelagonia region & 43.80 & 31.20 & 6.20 & 100.00 \\
\hline Polog region & 62.60 & 82.60 & 2.30 & 100.00 \\
\hline Northeast region & 15.10 & 55.00 & 10.00 & 100.00
\end{tabular}

Satisfaction with the work of the local government for finding solutions for opportunities in culture and sports activities $\mathbf{X}^{2}=163795$

\begin{tabular}{|l|c|c|c|c|}
\hline Vardar region & 48.80 & 36.20 & 15.00 & 100.00 \\
\hline East region & 53.80 & 42.40 & 3,80 & 100.00 \\
\hline Southwest region & 43.80 & 50.20 & 6.20 & 100.00 \\
\hline Southeast region & 43.80 & 40.00 & 16.20 & 100.00 \\
\hline Pelagonia region & 45.00 & 50.00 & 5.00 & 100.00 \\
\hline Polog region & 30.00 & 57.60 & 12.40 & 100.00 \\
\hline Northeast region & 11.20 & 73.80 & 15.00 & 100.00 \\
\hline Skopje region & 16.00 & 60.00 & 25.00 & 100.00 \\
\hline
\end{tabular}

The order for the second group of answers "dissatisfied" is reversed and the first place belongs to the solutions for opening new jobs $(52.40 \%)$, and the last place is for finding solutions in the water supply and sewage system (37.80\%). 
This general assessment of the functioning of the local government in resolving local problems, shows the most significant deviations, i.e. statistically significant correlation, from the aspect of the regional affiliation of the rural population.

For the strong connection between the regional affiliation and the assessment of the resolution of local problems, the high coefficient testifies: for the availability of social services (schools, kindergartens, hospitals) and shops $(\mathrm{C}=0.539)$, solutions in transport/carriage, construction and maintenance of roads $(C=0.521)$, opening of new jobs $(C=0.491)$, water supply and sewage solutions $(C=0.481)$ and solutions for opportunities in cultural and sports activities $(C=0.451)$.

Faced with the challenges of globalization, the local government should be able to lead and implement a policy, citizens should be well informed and involved in the policy-making processes. However, the population in the rural communities faces inadequately developed mechanisms of public participation, insufficient information, low educational level, a high degree of dependence of the old population, etc. Only by engaging-active relationship, citizens can provide real participation in democratic expression and satisfaction of their interests and needs. Therefore, the question we asked the respondents refers to their involvement in resolving the everyday problems in the rural community (the village).

Table 5: How much have you been involved in resolving the everyday problems in the rural community?

\begin{tabular}{|l|l|l|l|l|c|}
\hline & Average & Women & $15-29$ years & Housewives & Student \\
\hline Full & 15.90 & 6.50 & 4.30 & 8.90 & 0.00 \\
\hline Partially & 47,20 & 23.70 & 40.40 & 31.10 & 33.30 \\
\hline Little & 2.70 & 2,20 & 0.00 & 0.00 & 0.00 \\
\hline Not included & 34.20 & 67.60 & 55.30 & 60.00 & 66.70 \\
\hline Total & 100.00 & 100.00 & 100.00 & 100.00 & 100.00 \\
\hline
\end{tabular}

The responses we received indicate the following:

- The majority (47.20\%) of respondents state partial involvement in resolving of problems. This means that the population in the rural communities does not use all the opportunities that the system provides to participate and influence the decision-making process. This category includes almost every second citizen of the village which is very unfavourable data in itself.

- Second, according to the number of answers (about 34\%) is the category of village population that believes that it is not included at all. This means that every third respondent is not involved at all in resolving the problems of the village.

The concentration of the answers around the modality two, three, and four suggests that the rural population has a very self-critical attitude towards the participation in the resolution of everyday problems. This has indirectly expressed some degree of concern due to this attitude of the population, which was emphasized.

The following groups of respondents gave a practical and tougher assessment (in terms of the general distribution) of the involvement in solving the everyday problems in the village: $67.60 \%$ of women, $15-29$ years of age $(55.30 \%)$, housewives $(60.00 \%)$ and students $(66.70 \%)$.

\section{CONCLUSION}

The research indicates that the resolution of problems in rural communities in the Republic of Macedonia is far from the needs of the citizens, so that a large part of the population assesses the work of the local government as unsuccessful. This means that the influence of the local government is insufficient or absent precisely from the basic infrastructural needs of each rural community.

By the improvement of transport and infrastructure, rural communities will become places that will attract more visitors, migration will be reduced, and new opportunities for establishment of local businesses will emerge. This will contribute to the revival of rural communities.

Investing in physical infrastructure such as, building regional and local roads, building local water supply, sewerage and waste systems, improving the electricity supply and telecommunication facilities, will make rural areas attractive for the business, will raise value of the land, and will impove the quality of life. When planning the investments, local authorities should first give priority to the needs of the local population, and after that search for ways to bring investments to their local community as soon as possible.

During pre-elections politicians speak of democracy, rule of law, and prosperity of citizens, but after the elections they disappoint their electorate. After elections, citizens often complain that they do not get help from the local authorities which makes them feel hopeless and insecure. Therefore, citizens should be motivated and encouraged to participate in the decision-making process of the local authorities, and in that way feel that they can impact the situation and the course of activities at the local level. Citizens should be given the opportunity to present their problems, and their opinions to be taken into consideration.

In addition to the existing forms of participation of the citizens (voting, referendum, local -government councils), sitizens should seek and use other forms that give them the chance to lobby and influence public policy sush as, informal communication with the representatives of the local and cental authorities, formation of local associations, and reestablishing of the 'local communities' as institutions of the local population.

The high level of active participation of the rural population is important for the future of rural communities. Public participation should extend from sharing information through consultation to more active forms of participation, such as 
partnerships that involve the local population's strong influence on public and service policies. Effective inclusion of the local population is important for the good public policies and the good governance of the local government.

\section{REFERENCE}

1. Zikov, M.. 2006. The Challenges of Rural Development and Agribusinesses in Food Production. Proceedings of the scientific symposium with international participation Rural Space in New Development Conditions, Book 1, pp. 1-17 Faculty of Natural Sciences - Institute of Geography, Skopje.

2. Law on Balanced Regional Development. 2007. Official Gazette of the Republic of Macedonia No. 63.

3. Jakimovski, J. 2004. Rural Social Structure. Fiedrich Ebert Siftung, Skopje.

4. Jakimovski, J. and other. 2006. Distribution of Population and Sustainable Development, study of the Institute for Sociological, Political and Juridical Research, Skopje.

5. Jakimovski, J. 2017. Social Structure and Quality of Life in the Macedonian Village. Asian Journa, of Science and Tehnology, Vol. 8, Iss. 10, pp. 5932-5938.

6. Lazdinis, M. 2004. Third Report on Economic and social cohesion Luxembourg: office for official publications of the European Union. Available at: https://www.scribd.com/document/80756339/Agriculture-and-cohesion-Dinan

7. Regional Development Strategy of the Republic of Macedonia 2009-2019. 2009. Official Gazette of the Republic of Macedonia No. 119.

8. Survey on incame and living conditions, 2015. 2015.Statistical review: Incames, expenditures and prices, 2.4.16.15/863, State statistical office, republic od Macedonia, Skopje.

9. Uzunov, N., Georgiev, A., Nestorovski, M. 1988. Degree of (non) - synchronization between processes. Industrialization - deagrarization - migration and urbanization in SR Macedonia, Komunist, Skopje 